\title{
Patterns of Activity Coding Discrimination of Auditory Stimuli Differ between Mid- and Posterolateral Thalamus of Cats
}

\author{
C. D. Woody, O. Melamed, and V. Chizhevsky \\ Mental Retardation Research Center, Brain Research Institute, UCLA Medical Center, Los Angeles, California 90024
}

The auditory function of units in the mid- (lateralis dorsalis
and centrolateral nuclei) and posterolateral (lateralis pos-
terior-pulvinar complex) thalamus of cats was assessed
during performance of conditioned eye blink responses (CRs)
elicited discriminatively by a forward-paired, 70 dB click con-
ditioned stimulus (CS) as opposed to a backward-paired, 70
dB hiss discriminative stimulus (DS). Discharges in response
to the CS or DS were found in over $40 \%$ of units tested in
each area, with onset latencies as short as $28-32$ msec in
mid-thalamus and 14 msec in posterolateral thalamus. The
results provide evidence that both mid- and posterolateral
thalamic regions of cats contain sufficient numbers of au-
ditory responsive neurons to be considered part of the au-
ditory system functionally.

Patterns of activity changed after conditioning discriminative responses to the click CS. In mid-thalamus, the ratio of CS-evoked activity to baseline activity increased relative to levels found before conditioning. This increase was attributable to an increase in the magnitude of response to the CS. In posterolateral thalamus, an increase in the signal : noise ratio of activity in response to the CS was also found after conditioning, but this increase depended in large part on a decrease in the rate of baseline firing. Posterolateral thalamic units had substantially higher mean rates of baseline firing than mid-thalamic units before any conditioning sessions were begun. In all, different rates of baseline activity, means of enhancing activity in response to the click CS, and onsets of response were found at these two adjacent thalamic regions in which the unit response to the CS became greater than that to the DS after conditioning. We conclude that each region makes a separate contribution to information processing needed to discriminate effectively between auditory stimuli of different functional significance.

The role in audition of thalamic nuclei other than the wellknown auditory relay nucleus, the medial geniculate body, is poorly understood. Two regions of thalamus, the posterolateral and mid-thalamic regions, have anatomical connections that could possibly serve auditory functions (Heath and Jones, 1971; Graybiel, 1972; Jones and Leavitt, 1974; Macchi et al., 1977; Steriadc ct al., 1977; Irvine and Phillips, 1982; Imig and Morel, 1983; LeDoux et al., 1990), but responses of single neurons of these regions to auditory discriminative stimuli have never been described in cats.

Received Jan. 7, 1991; revised June 3, 1991; accepted June 10, 1991

This research was supported by USPHS Grant NS 25510.

Correspondence should be addressed to Dr. C. D. Woody, UCLA Medical Center, Room 58-232, NPI, 760 Westwood Plaza, Los Angeles, CA 90024.

Copyright (C) 1991 Society for Neuroscience 0270-6474/91/113379-09\$05.00/0
One early study in rats found many short-latency auditory responses in the pulvinar that changed with conditioning (Olds et al., 1972), but a subsequent study in cats failed to find any auditory responsive units in this nuclear complex or in the adjacent lateralis posterior nucleus (Phillips and Irvine, 1979). [Other studies in cats have demonstrated auditory responsive units in the centre median-parafascicular nuclei complex (Irvine and Phillips, 1982), the posterior (PO) region (Phillips and Irvine, 1979; Imig and Morel, 1985), and in rostral thalamus (Woody et al., 1991b).]

This study tested the hypothesis that auditory responsive units could be found in the mid- and posterolateral thalamus of conscious cats and assessed differences in auditory information processing between neurons of these regions. Patterns and latencies of response to click and hiss stimuli, as well as magnitudes of response relative to baseline rates of discharge, were used to make these assessments in naive animals and in conditioned animals in which a blink conditioned response (CR) was elicited discriminatively by one of the stimuli.

\section{Materials and Methods}

Intracellular (IC) and extracellular (EC) recordings were obtained from single units of the thalamus of nine cats (weight, $2.5-3.0 \mathrm{~kg}$ ) while the animals received presentations of click and hiss stimuli (see further details below). The cats were prepared for recording as described previously in detail (Woody and Black-Cleworth, 1973; Woody et al., 1984). Stainless-steel screws were implanted into the skulls of the animals under $\mathrm{Na}$ pentobarbital anesthesia $(35 \mathrm{mg} / \mathrm{kg}$, i.p.). The screws were used to fix the head to a stabilizing frame during later, conscious training/recording sessions. Penicillin $\mathrm{G}(150,000 \mathrm{U}, \mathrm{i} . \mathrm{m}$.) and benzathine penicillin $\mathrm{G}(150,000 \mathrm{U}$, i.m.) were given on the day of surgery, $3 \mathrm{~d}$ later during the recovery period, and at 1 week intervals thereafter, as needed. The cats were loosely restrained by placing their bodies in cloth sleeves during awake recording sessions. Their behavior was continuously obscrved to cvaluate the comfort of the animals, and the studies were discontinued if the animals gave any signs of discomfort such as vocalization and hyperactivity.

Bipolar recordings of EMG activity were obtained from the orbicularis oculi (eye) and levator oris (nose) muscles with Grass E2 subdermal electrodes led to differential amplifiers (Electronics for Life Sciences, ELSDA-1). EMG activity was analyzed after half-wave rectification and further amplification. Calibrations in figures designate amplifier gain, which was kept the same while recording EMG responses to the conditioned stimulus (CS) and discriminative stimulus (DS). While recordings were being made, averages of every three responses $\left(R_{1-3}, R_{2-4}\right.$, etc.) were displayed on a video terminal to permit continuous monitoring of eye blink performance elicited by the CS and DS. The EMG averages were more sensitive detectors of conditioned responses and learning savings than was direct observation of eyelid movement. Thus, EMG averages (left orbicularis oculis unless otherwise specified) were used when correlating unit activity with effects of conditioning.

$\mathrm{EC}$ and IC unit activity were recorded with a Dagan high-impedance amplifier and stored on FM tape (DC to $5000 \mathrm{~Hz}$ ) together with the simultaneously obtained EMG data. Analyses of EC activity were con- 

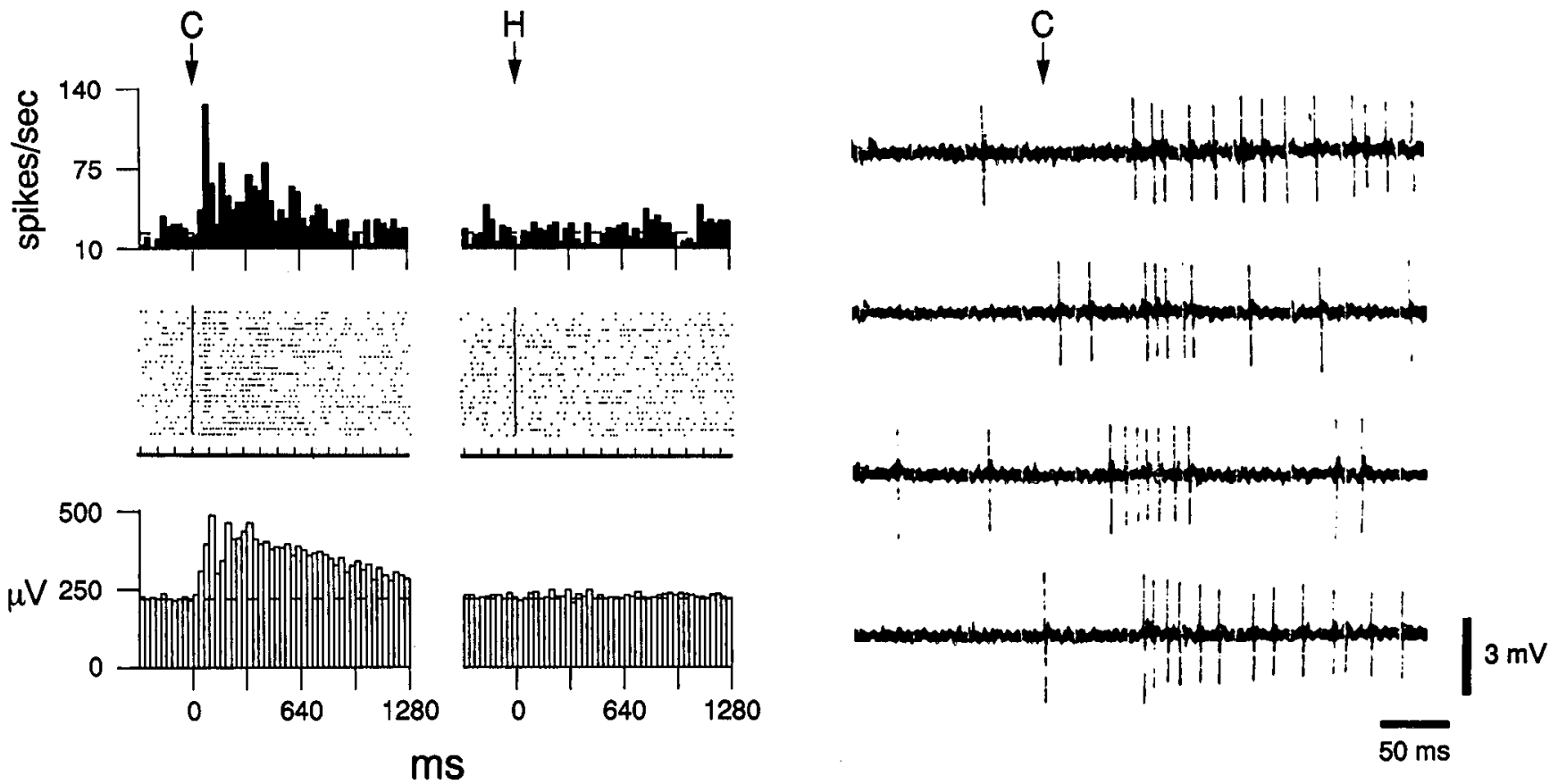

Figure 1. Data from a single-unit recorded from the pulvinar of an animal conditioned to blink in response to the click CS. Left: top, Histograms of unit activity to the click CS $(C)$ and hiss DS $(H)$. Times of delivery of the auditory stimuli is shown by arrows. No correction was made for 1 msec air conduction to ears of animal. Middle, Raster of responses to serial presentations of the CS and DS (time scale in increments of 100 msec); vertical bars designate stimulus delivery. Bottom, Histograms of the concurrently recorded EMG activity from the orbicularis oculi muscles involved in production of the blink CR; stimulus delivery was at time 0 . Right, Responses of the unit to four presentations of the CS (C, arrow).

fined to spikes of $<20 \mathrm{mV}$ amplitude without an accompanying $\mathrm{DC}$ shift. Analyses of IC activity were confined to spikes with accompanying DC shifts, the latter averaging $-55 \mathrm{mV}$ after penetration. The satisfactory condition of the studied cells was indicated by the ability to obtain recordings of activity with low, stable rates of baseline discharge. Also, as in earlier studies (Woody and Black-Cleworth, 1973), no significant differences were found between patterns of spike activity recorded intracellularly and those recorded extracellularly. Consequently, EC and IC data were combined when analyzing patterns of unit activity.

Electrodes were pulled from $1.5-2.0 \mathrm{~mm}$ (o.d.) theta tubing. When filled with $2.5 \%$ Phaseolus lectin (PHA-L; Vector Labs) in $3 \mathrm{M} \mathrm{KCl}$ (buffered with sodium phosphate to $\mathrm{pH} 7.4$ ) and connected on both sides with $\mathrm{Ag} / \mathrm{AgCl}$ wire, the resistances of the electrodes used for intracellular recordings ranged from 50 to $15 \mathrm{M} \Omega$ (and lower for electrodes filled with $\mathrm{KCl}$ alone used for extracellular recordings). Capacitance compensation of each electrode was adjusted after insertion into the cortex.

Patterns of unit activity were evaluated using averages of activity made within and across animals. The averages were obtained from pooled analyses of the activity of single units (e.g., Fig. 1) in which spike occurrences were detected with a threshold discriminator (Frederick Haer). Peristimulus time histograms of spike occurrences were made

\begin{tabular}{|c|c|c|c|c|c|c|}
\hline & & Cells (\% & & & & \\
\hline & State & B & $\mathrm{C}$ & $\mathbf{H}$ & 0 & Total \\
\hline Mid-thalam & & & & & & \\
\hline Inclusive & ADP & $48 / 117$ & $19 / 46$ & $14 / 35$ & $19 / 48$ & 246 \\
\hline & COND & $47 / 122$ & $17 / 43$ & $11 / 29$ & $25 / 63$ & 257 \\
\hline Selective & ADP & $17 / 40$ & $15 / 38$ & $12 / 31$ & $56 / 137$ & 246 \\
\hline & COND & $16 / 41$ & $15 / 38$ & $10 / 27$ & $59 / 151$ & 257 \\
\hline $\begin{array}{l}\text { Posterolater } \\
\text { thalamus }\end{array}$ & & & & & & \\
\hline Inclusive & ADP & $52 / 76$ & $16 / 23$ & $17 / 24$ & $15 / 22$ & 145 \\
\hline & COND & $53 / 81$ & $17 / 27$ & $13 / 20$ & $17 / 26$ & 154 \\
\hline Selective & ADP & $19 / 28$ & $15 / 21$ & $22 / 32^{a}$ & $44 / 64$ & 145 \\
\hline & COND & $22 / 34$ & $14 / 21$ & $10 / 16^{a}$ & $54 / 83$ & 154 \\
\hline
\end{tabular}

Inclusive: response defined by activity $>$ peak of baseline in any $4 \mathrm{msec}$ period from 0 to $160 \mathrm{msec}$ after click and hiss, respectively. Selective: response defined by activity $\geq$ two discharges above peak of baseline in any 4 msec period from 0 to $160 \mathrm{msec}$ after click and hiss, respectively. Cells: B, responsive to both click and hiss; C, responsive to click only; $\mathrm{H}$, responsive to hiss only; 0 , unresponsive to click or hiss. ADP, Before conditioning; COND, after conditioning.

a Number of $\mathrm{H}$-responsive cells differed before and after conditioning $\left(p<0.01, \chi^{2}\right.$ test) using selective criteria to define a responsive cell. 


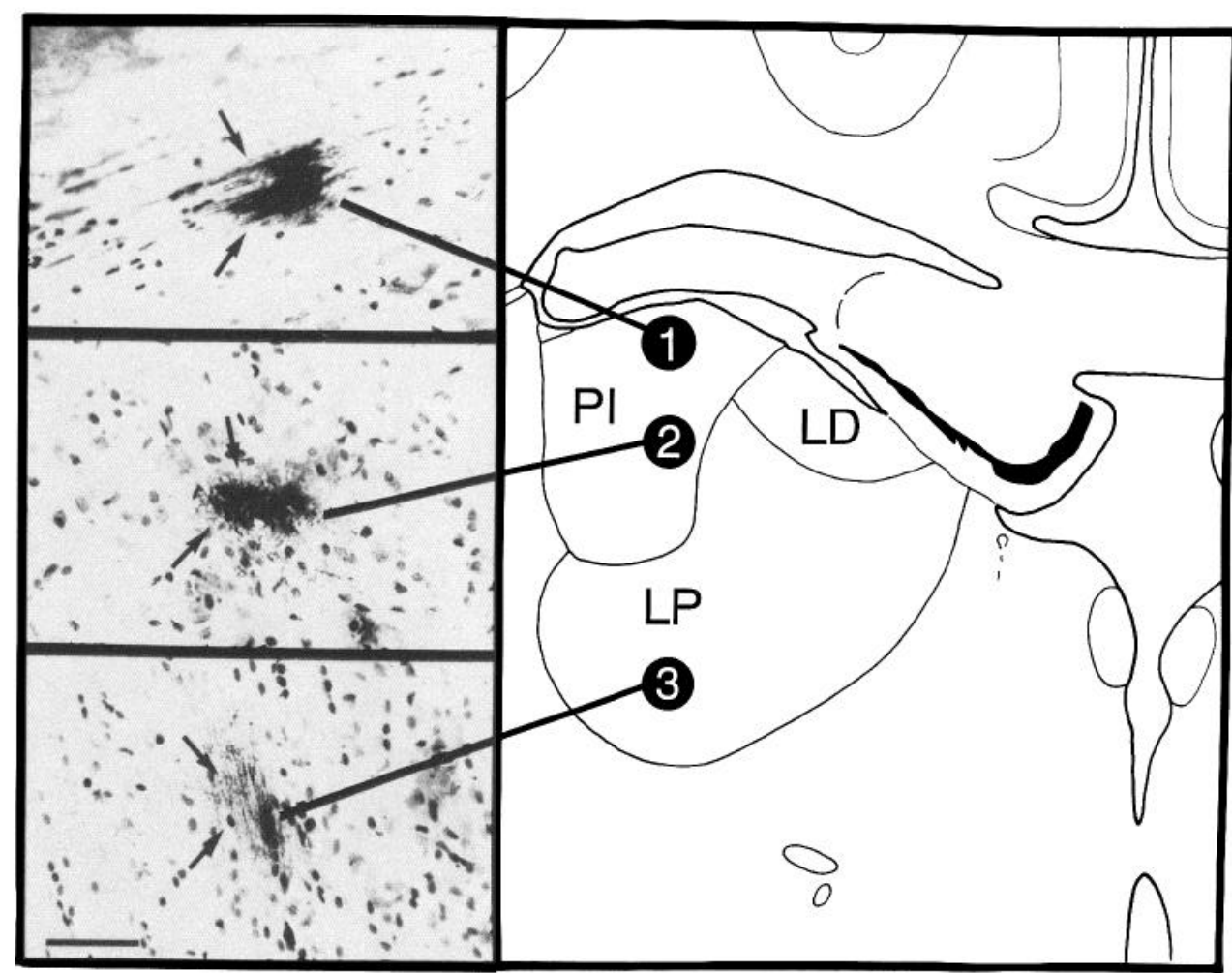

Figure 2. Example of locations marked by PHA-L in a single animal. Locations 1 and 2 were in the pulvinar $(P l)$. Location 3 was in the $L P$ nucleus. The caudal portion of the $L D$ nucleus is seen just medially. Scale bar for photomicrographs (lower left), $50 \mu \mathrm{m}$. The drawing to the right is $7 \mathrm{~mm}$ anterior to the interaural line (Snider and Niemer, 1961). with reference to times of CS and DS onset (uncorrected for $1 \mathrm{msec}$ air conduction delay between sound source and ears of animal) for each cell that was studied. Then the data from the single units, each cell weighted equally, were averaged.

Auditory receptivity of units (Table 1) was defined in two ways: (1) "inclusively" on the basis of increased activity (above the peak of baseline activity in each $4 \mathrm{msec}$ bin of the two $40 \mathrm{msec}$ periods of discharge preceding the CS and DS) at any time in the $160 \mathrm{msec}$ period following CS and DS presentation and (2) "selectively" on the basis of more substantially increased activity ( $\geq 2$ discharges above the peak, per 4 $\mathrm{msec}$, of both $40 \mathrm{msec}$ periods of preceding baseline activity), also at any time during the $160 \mathrm{msec}$ period following CS or DS presentation. [Each criterion was devised so that the latency of any response to the CS (or DS) would be unbiased within the $160 \mathrm{msec}$ period after stimulation.] The selective criterion was used for estimating percentages of auditory responsive units since it posed a more rigorous test of responsiveness. The inclusive criterion was used to ensure that weakly responsive cells in a distributed processing system would be sampled and included in assessment of patterns of response. Decreases in activity in response to the CS may have occurred in some cells but were not assessed because of the difficulty in detecting decreases in cells with low rates of baseline activity.

Electrodes were introduced into the thalamus using a previously implanted stereotaxic guide tube. The depth at which each unit was recorded was noted. Locations of recordings were determined using the approach of Steriade and Glenn (1982), that is, from serial sections of tissue with reconstructions of electrode tracts plus associated microdrive coordinates, or, alternatively, by extracellular (and, in a few instances, intracellular) pressure injections of PHA-L (sometimes mixed with $4 \%$ HRP) made at the conclusion of recordings (Fig. 2). [Our methodologies for the pressure injections were described earlier (Sakai et al., 1978).] The morphologies of intracellularly and extracellularly marked neurons from these and other, more rostral, thalamic regions have been described in a separate report (Chizhevsky et al., 1990). The procedure of Porter and Sakamoto (1988), based on the method of Gerfen and Sawchenko (1984), was used to react the tissue for PHA-L. The peroxidase-diaminobenzidine treatment used as part of that procedure also detected the original HRP when present. Loci at which markings were found (center for multiple markings) for each animal are shown in Figure 3. Recordings were obtained within 1-2 $\mathrm{mm}$ of these loci in the anterior-posterior or medial-lateral planes and $2-3 \mathrm{~mm}$ vertically, which sufficed to localize the recordings within the defined mid- or posterolateral thalamic regions.
Behavioral training. Conditioned (CS), unconditioned (US), hypothalamic (HS), and discriminative (DS) stimuli were presented in timed sequences during trials of behavioral conditioning (see Kim et al., 1983, and Hirano et al., 1987, for any details not given below). The click CS was generated by a rectangular pulse of $1 \mathrm{msec}$ duration (delivered to a loudspeaker placed 1-2 feet in front of the animal). The clicks were of $70 \mathrm{~dB}$ intensity (General Radio Company, dB meter type 1565-A) measured at the ears of the animals. A hiss of comparable intensity to the click (see Kim et al., 1983, for amplified earphone recordings of the stimuli) was employed as the DS. A tap delivered to the glabella served as the US. It was produced by means of a small metal rod driven electromechanically by a solenoid to strike a screw that was previously implanted in the glabella (see Woody et al., 1974, for complete details). HS consisted of a train of four electrical stimuli delivered to the lateral hypothalamic region as described more fully below.

Adaptation consisted of an initial training period during which click and hiss were presented $4.4 \mathrm{sec}$ apart. Conditioning was accomplished thereafter by pairing click CS with glabella tap US and HS at interstimulus intervals of 570 and $10 \mathrm{msec}$, respectively. The hiss DS was presented $3.8 \mathrm{sec}$ after the HS. A $10 \mathrm{sec}$ intertrial interval was used to reduce the total time between the beginning of training and establishment of the conditioned blink response. This facilitated electrophysiological studies of unit activity, which were made during 10-20 repeated presentations of the CS and DS without US or HS (as during adaptation). These testing trials were followed by repeated conditioning trials to prevent extinction of the CR. Delivery of CS, US, HS, and DS during training and testing was controlled by means of the PDP 11-44 computer. EMG responses to the CS and DS were measured so that unit activity could be compared with production of the CR.

These initial studies did not evaluate the associative consequences of conditioning on unit activity. Earlier studies indicated that development of the conditioned behavior depended on the order of stimulus presentation (Woody et al., 1974; Kim et al., 1983), that the hiss was a satisfactory CS when the order of presentation was reversed (Engel and Woody, 1972; Hirano et al., 1987), and that pseudorandom pairing of CS, DS, and US did not lead to acquisition of the CR (Woody et al., 1976). Behavioral studies were also performed earlier that evaluated other associative consequences of pairing these stimuli (Kim et al., 1983; Hirano et al., 1987). The results indicated that the behavioral CR met the usual tests of associative conditioning.

Hypothalamic stimulation. Electrical stimulation of the hypothalamus was accomplished with bipolar, stainless-steel, concentric elec- 


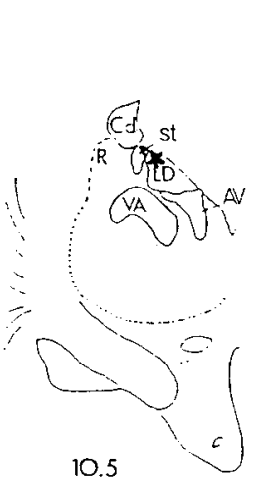

A
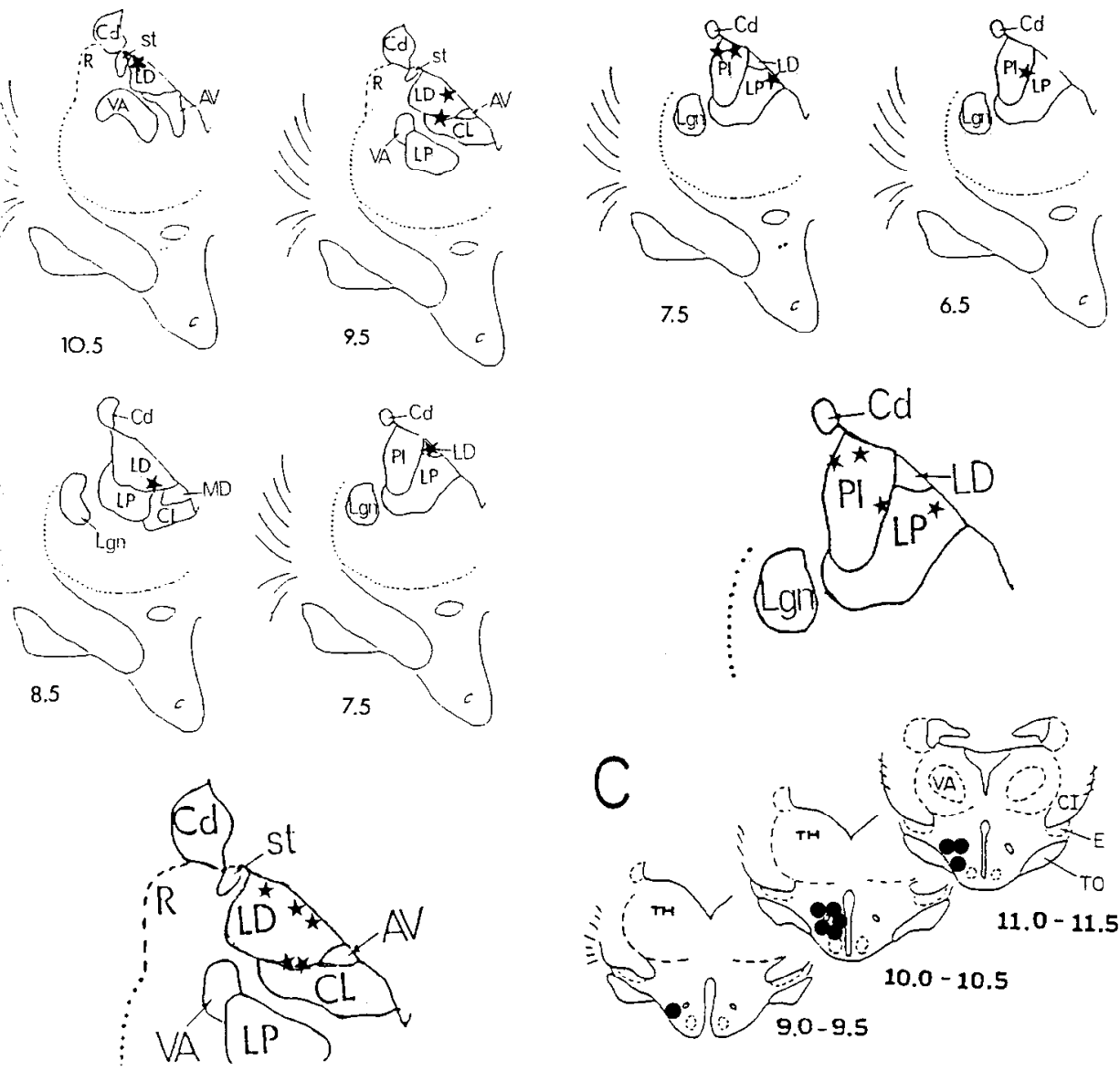

Figure 3. Locations of mid-thalamus $(A)$ and posterolateral thalamus $(B)$ from which recordings were made. [Numbers are anterior stereotaxic planes in millimeters from interaural line (Snider and Niemer, 1961).] Below $A$ and $B$, respectively, are composite sketches of the relative locations of recording in each animal. $A V$, anterior ventral; $C d$, caudatc; $C L$, centralis latcralis (ccntrolateral); $L D$, lateralis dorsalis; $L g n$, lateral geniculate; $L P$, lateralis posterior; $M D$, medialis dorsalis; $P l$, pulvinar; $R$, nucleus reticularis; $s t$, stria terminalis; $V A$, ventralis anterior. In $C$ are shown the locations of hypothalamic stimulating electrodes at which HS (see Materials and Methods) were delivered. $C I$, internal capsule; $E$, entopeduncular nucleus; $T h$, thalamus; $T O$, optic tract. Tissue was cut in the parasagittal plane. Summaries of (reconstructed) data were drawn in the more familiar horizontal plane. trodes (David Kopf Instruments, NE 100). The diameters of the concentric electrodes were 0.2 and $0.5 \mathrm{~mm}$, respectively, each with an exposed tip length of $0.5 \mathrm{~mm}$. Each train of hypothalamic stimulation (HS) consisted of four brief rectangular pulses of 100-200 $\mu$ sec duration, presented at $50 \mathrm{~Hz}$. Currents of $0.6-5 \mathrm{~mA}$ were used with intensities adjusted to obtain optimal behavioral effects. The lateral hypothalamic region was selected as the locus of stimulation on the basis of earlier studies in which HS was used successfully to produce rapidly acquired blink CRs (Kim et al., 1983). HS produced facial (blink) movements and abdominal muscle contractions, but no hissing or piloerection. [Rapid conditioning of cortical units can be accomplished by local ionophoretic application of glutamate, intracortically, in lieu of HS (Woody et al., 199 1a).] Since most of the cats required electrical HS of $>1 \mathrm{~mA}$ intensity to learn CRs rapidly, the cffects of HS werc not likcly to have becn confined to the local regions. At the end of each experiment (10-14 d after the last injection of PHA-L), a steady current ( $1 \mathrm{~mA}, 20 \mathrm{sec})$ was delivered through the HS electrode in order to produce a small lesion. Animals were then killed with sodium pentobarbital and perfused with physiological saline followed by $10 \%$ formalin or $4 \%$ paraformaldehyde to confirm locations of electrodes by histologic analysis. (The locations are shown in Fig. 3C.)

\section{Results}

Unit activity to auditory stimuli before and after conditioning

Recordings were made from a total of 802 units from midthalamic [lateralis dorsalis (LD) and centrolateral (CL) nuclei] or posterolateral thalamic regions [pulvinar complex (PL) and anterior portion of the lateralis posterior (LP) nucleus]. Responses to click CS and hiss DS were studied before and (in separate units) after discriminative conditioning of an eye blink response elicited selectively by the CS. Units with increased discharges to the CS or DS, such as the pulvinar unit shown in Figure 1, were found in each nucleus within each region. Figure 3 shows the locations from which unit recordings were obtained in the nine cats that constituted these studies.

Grand averages of the activity of all units recorded from the mid-thalamus ( $n=503$ ) werc comparcd with those from the posterolateral thalamus ( $n=299$; Fig. 4 ). Substantial differences in patterns of response were found between these regions. Responses in posterolateral thalamus began earlier and were of shorter duration than those in mid-thalamus and were associated with a late $(320$ to $\gg 640 \mathrm{msec}$ ) inhibition of discharge below prestimulus baseline levels. More detailed comparisons (Fig. 5) disclosed additional differences, as follows.

Before conditioning (Fig. 5Ia,IIa), higher mean rates of spontaneous activity $(t=81.4, \mathrm{df}=390, p<0.00001)$ were recorded from posterolateral thalamus $[22.9 \pm 0.6$ spikes $(\mathrm{spk}) / \mathrm{sec}]$ than from mid-thalamus $(17.5 \pm 0.6 \mathrm{spk} / \mathrm{sec})$. Recordings made in each of these locations within single animals before conditioning [e.g., Fig. $5 I c$ : mean, $19.9 \pm 0.6 \mathrm{spk} / \mathrm{sec}(68 \mathrm{cells})$; and IIc: mean, $27.2 \pm 1.25 \mathrm{spk} / \mathrm{sec}$ (22 cells); $t=35.8, \mathrm{df}=88, p<$ $0.0001]$ indicated that these differences were a function of the location of recording and did not represent idiosyncratic differences between animals. In the grand averages (Fig. 5Ia,IIa), responses to the click CS and hiss DS were found before conditioning that were $\gg 3 Z$ (Winer, 1971) above baseline in units of the posterolateral thalamus and $2-3 Z$ above baseline in the 


\section{Mid-Thalamus}

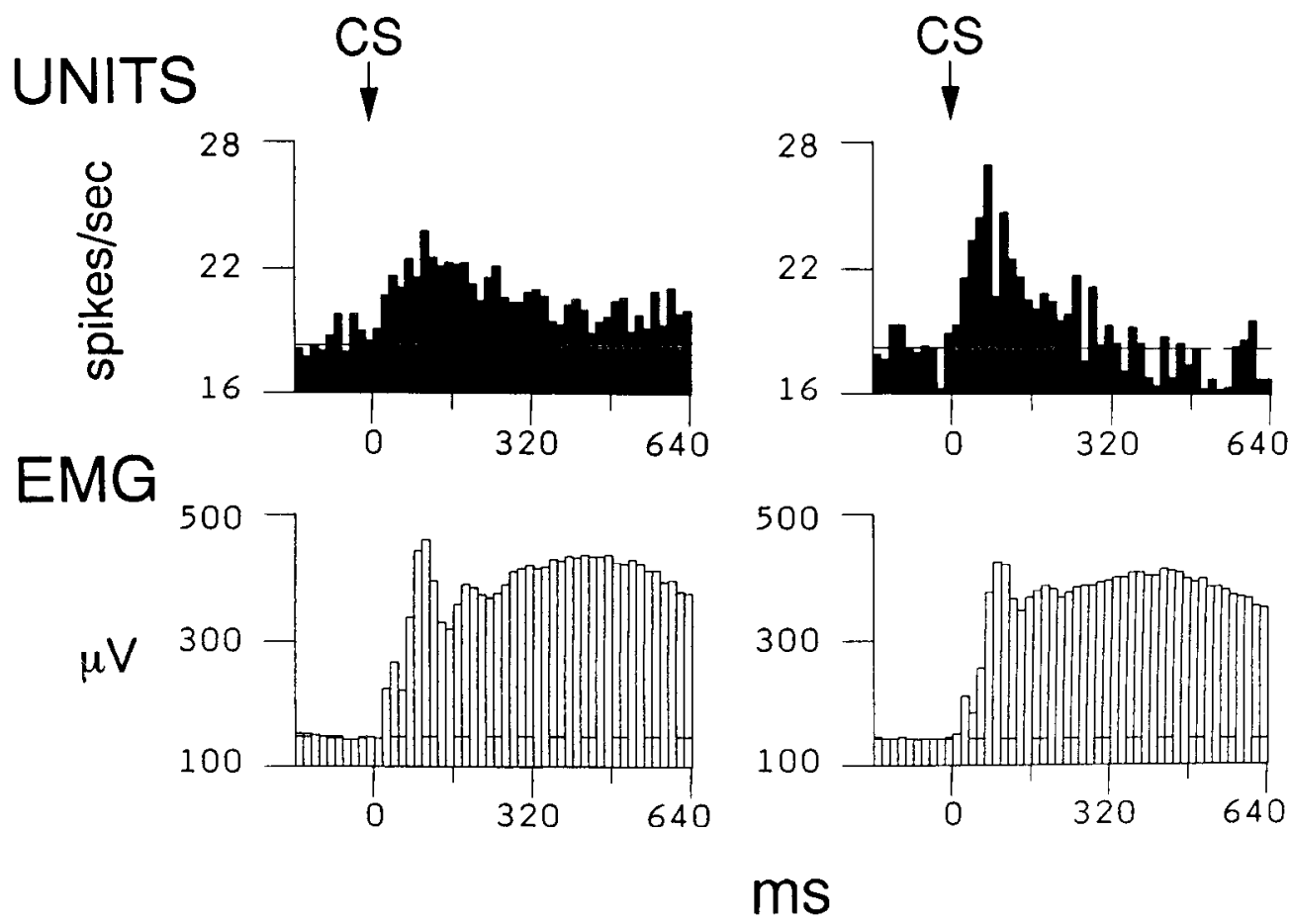

\section{Posterolateral Thalamus}

Figure 4. Differences in averaged patterns of activity to click CS recorded from mid- and posterolateral thalamus of conditioned animals. Histograms are the averages of all spike activity (solid bars) and corresponding EMG activity (open bars) obtained from all cells, all trials, and all cats after conditioning (left, $n=257$ cells; right, $n=154$ cells). The click CS was delivered at time 0 (vertical arrows). Calibrations for spike activity (spikes per second) and EMG activity $(\mu \mathrm{V})$ are as shown. Time scale is in milliseconds. Baseline levels of spike discharge and EMG activity (broken lines) are the mean of the activity in the period from 0 to $380 \mathrm{msec}$ preceding delivery of the CS. mid-thalamus. (The SD of the mean baseline activity was taken as an index of $Z$, the $S E$ unit of a normally distributed population with SD equal to $Z$, where $1 Z$ was expected to contain 0.841 of the distribution, and $2 Z$ and $3 Z$ were expected to contain 0.977 and 0.9987 of the distribution.)

After conditioning, each region exhibited different changes in the patterns of unit response to the CS and DS. In the midthalamus, the magnitude of response to the CS increased well above the $3 Z$ level (Fig. 5IIIa) in the period 32-320 msec after CS delivery. The response to the CS became larger than that to the DS. Spontaneous activity increased slightly from $17.5 \pm 0.6$ to $18.3 \pm 0.6 \mathrm{spk} / \mathrm{sec}$.

In the posterolateral thalamus (Fig. 5IVa), the magnitude of response to the CS was not increased relative to that before conditioning. There was, however, a substantial increase in the signal : noise $(\mathrm{S}: \mathrm{N})$ ratio of response to the $\mathrm{CS}(\gg 3 Z)$ together with a reduction of baseline firing from $22.9 \pm 0.6$ to $18.4 \pm$ $0.6 \mathrm{spk} / \mathrm{sec}(t=60.7, \mathrm{df}=299, p<0.00001)$ accompanied by a $3 \mathrm{mV}$ hyperpolarization of the mean intracellular resting potential, and the response to the CS became larger than that to the DS.

Recordings of activity from different loci within the same animals after conditioning (e.g., Fig. $5 I I I C, I V_{C}$ ) showed patterns of discharge corresponding to those of the overall cell populations, indicating that differences between animals were not responsible for the differences in patterns of activity between thalamic regions after conditioning.

\section{Activity before and after conditioning within single animals}

Patterns of activity were also compared within a single thalamic region in single animals before and after conditioning (Fig. 6). In the cat with recordings from mid-thalamus (Fig. 6, left), the magnitude of response to the $C S$ increased above the $3 Z$ level, and the onset of increased unit activity did not precede initiation of the CR (Fig. $6 c$, left). In the cat with recordings from posterolateral thalamus (Fig. 6, right), there was little increase in the peak magnitude of response to the CS or DS, but the $S: N$ ratio of the response increased together with a decrease in the spontaneous activity from 22.1 to $15.4 \mathrm{spk} / \mathrm{sec}(t=25.3, \mathrm{df}=$ $83, p<0.0001)$. The earliest increase in activity in response to the CS was well above $3 Z$ of the baseline and preceded initiation of the CR. These changes in activity within single animals were similar to those found in the overall cell populations after conditioning.

\section{Latencies of response}

The onset latencies of response to the CS were assessed in more detail in units identified as having an increased discharge in the $160 \mathrm{msec}$ following presentation of the CS. Two different criteria (inclusive or selective; see Materials and Methods) were used to define the auditory responsive units. Data using the inclusive criterion (Fig. 7, $a, d$ ) agreed with data using the selective criterion (Fig. $7, e, f$ ) in showing that increased activity in the posterolateral thalamus preceded initiation of the CR while that in the mid-thalamus did not. [The analysis of the CS-responsive subset of neurons of the posterolateral thalamus in Fig. 7 showed a level of baseline activity too high to account for the full decrease in activity in the total population (Fig. 5). Hence, other cells must have been principally responsible for this decrease (cf. Weinberger and Diamond, 1987).] In mid-thalamus, the increase in unit activity had onsets approximately $28-32 \mathrm{msec}$ after delivery of the CS. In posterolateral thalamus (Fig. 7, far right), there was a small $(2-3 Z)$ increase in unit activity preceding initiation of the CR with onset approximately $14 \mathrm{msec}$ 


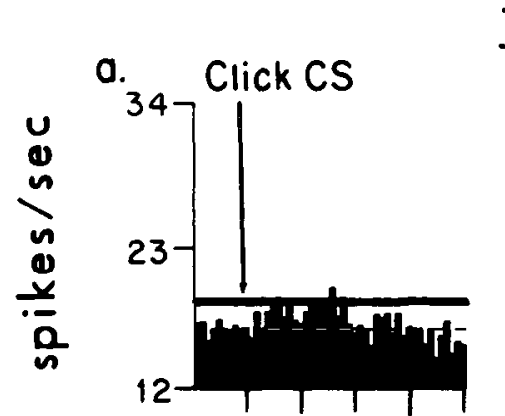

b.

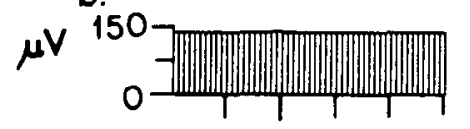

c.

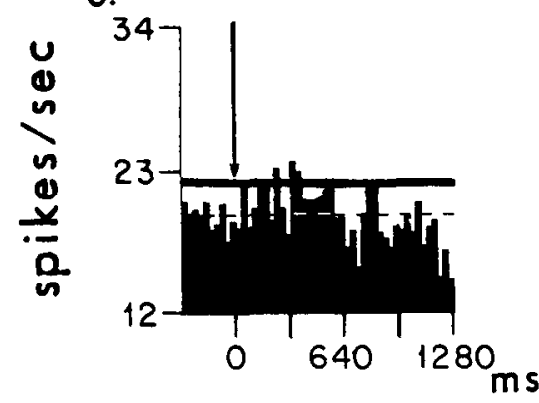

III

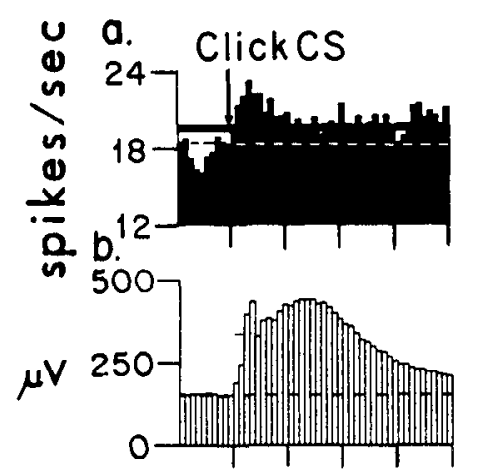

c.

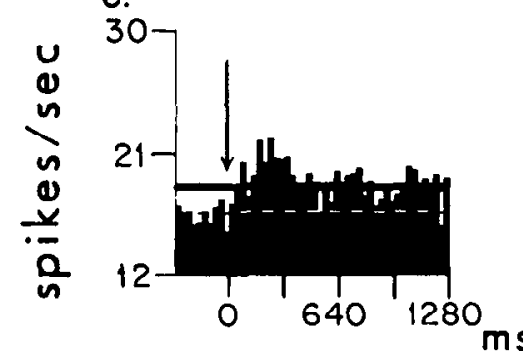

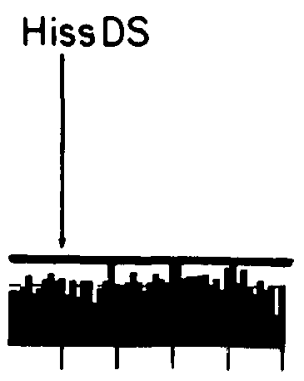
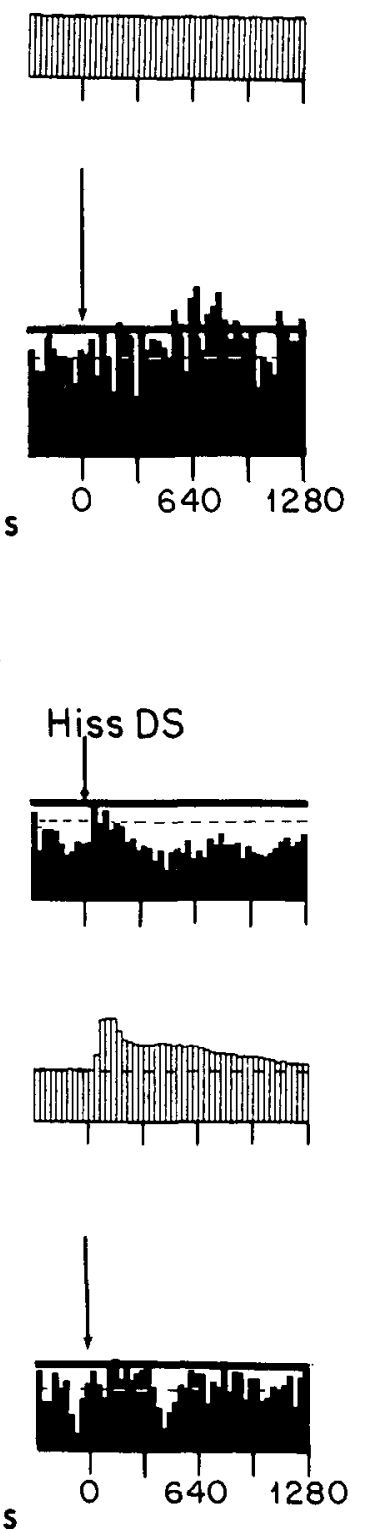

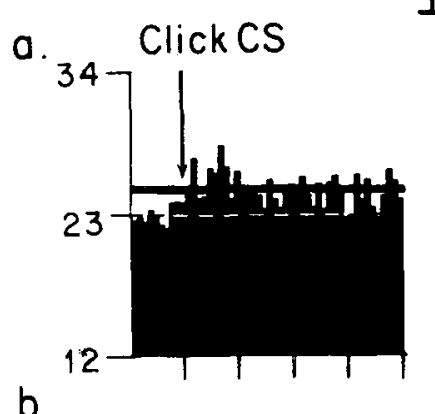

II
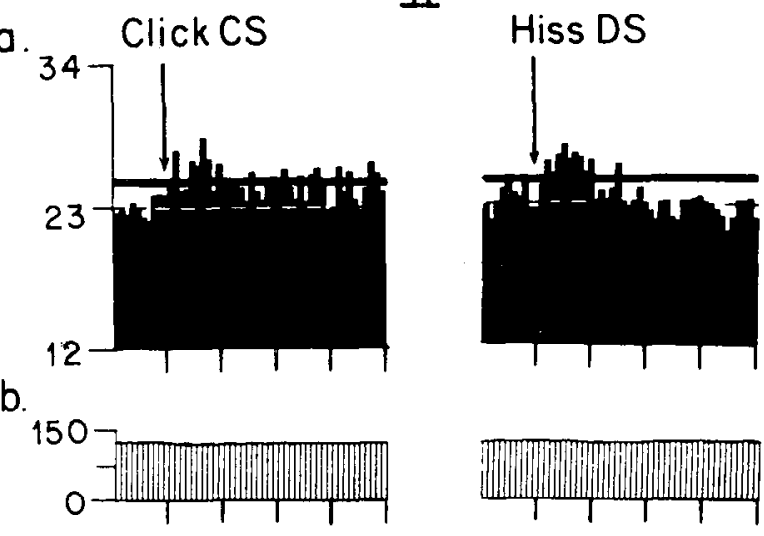

c.

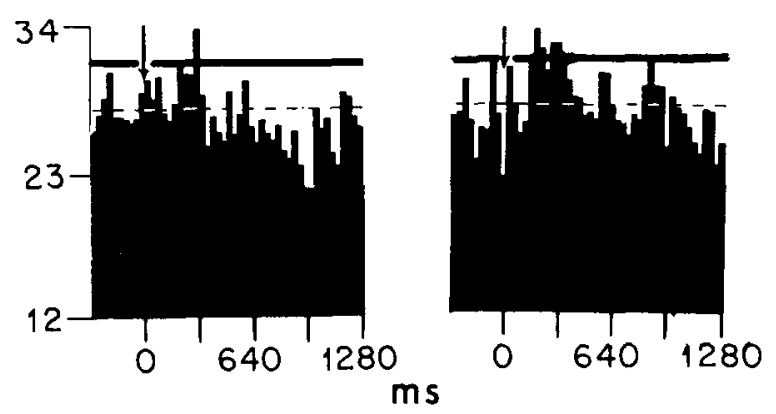

IV
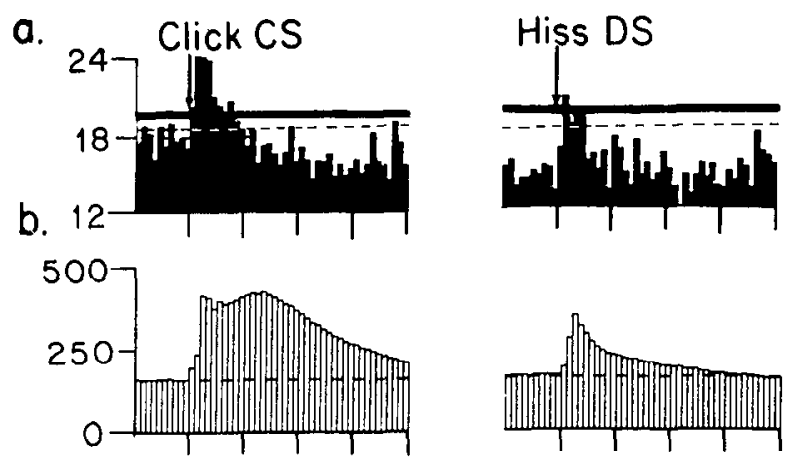

c.

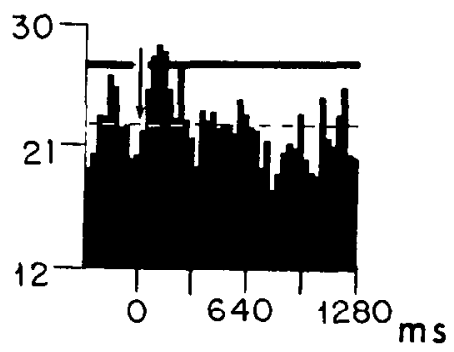

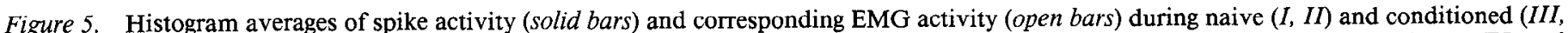

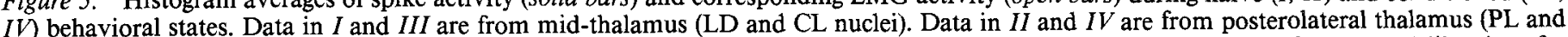

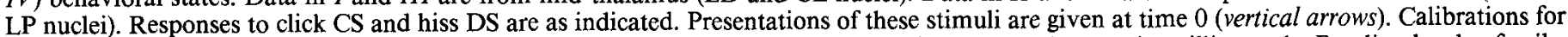

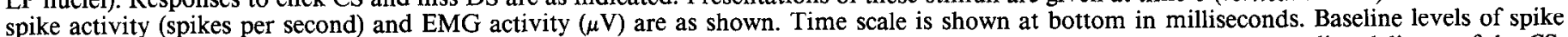

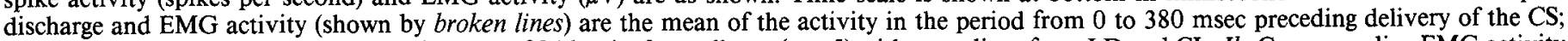

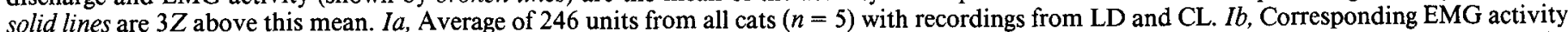

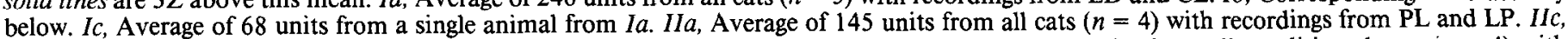

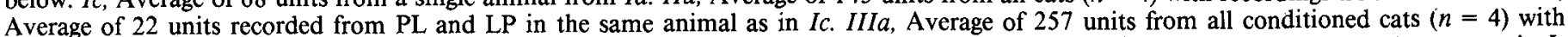

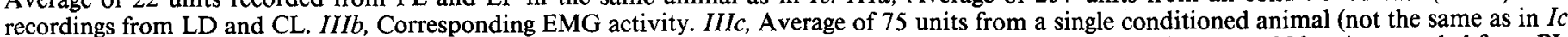

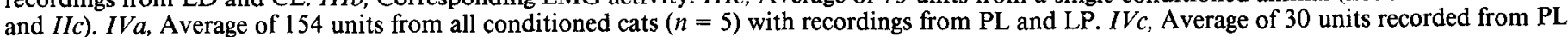
and LP in the same animal as in $I I I C$. 
a
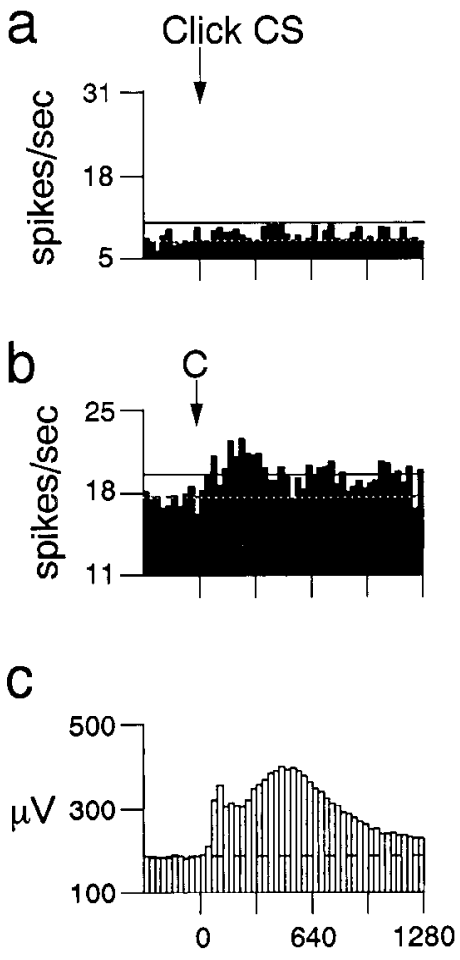

ms

Figure 6. Histogram averages of spike activity (solid bars) of units from mid-thalamus of a singlc animal (left $)$ beforc ( $a ; n=52$ units) and after ( $b ; n=75$ units) conditioning. EMG data (open bars) corresponding to the spike data in $b$ are shown in $c$. To the right are data from the posterolateral thalamus of another animal before $(a ; n=35$ units) and after ( $b ; n=50$ units) conditioning. $c$, EMG activity associated with $b$. An improvement in the $S: N$ ratio of activity in response to the CS occurred in each animal after conditioning. Data are from all cells in each cat that responded to the CS with an increased discharge in the initial $160 \mathrm{msec}$ after stimulus delivery (C and B cells, inclusive criteria). Calibrations for spike and EMG activity are the same for each animal; other calibrations and labeling are as in Figure 5. after CS delivery, and individual cells were found with increased discharge 12-16 msec after presenting the CS.

\section{Proportions of CS- and DS-responsive units}

After dividing units into those responsive to click, hiss, both click and hiss (same selective and inclusive criteria for response as earlier), and the remaining unresponsive (or less responsive) cells, the proportions of units before and after conditioning were examined (Table 1). Before conditioning, $44 \%$ of mid-thalamic and $56 \%$ of posterolateral thalamic units showed responses to click or hiss defined by selective criterion. After conditioning, $41 \%$ and $46 \%$, respectively, of units from these regions showed such responses. Thus, discharges in response to the CS or DS were found in more than $40 \%$ of units from each thalamic area studied.

After conditioning, the proportion of DS responsive units recorded from posterolateral thalamus decreased $\left(p<0.01, \chi^{2}\right.$ test; Table 1). This change was correlated with the animals' ability to respond preferentially to the CS, as opposed to the DS, in performing the CR.

\section{Discussion}

Over $40 \%$ of cells in mid- and posterolateral thalamic regions showed increases in activity in response to click or hiss (Table 1). The increases were found before as well as after the animals were conditioned to respond discriminatively to the stimuli. The finding of auditory responsive cells in the mid-thalamus ( $L D$ and $C L$ nuclei) of cats is in agreement with a concurrent finding in the LD nucleus of rabbits (Gabriel et al., 1988; cf. Melamed and Woody, 1989). [Note, however, that the LD and $\mathrm{CL}$ nuclei are not functionally homogeneous (Heath and Jones, 1971; Jones and Leavitt, 1974) and that the present data were grouped into a mid-thalamic region on the basis of electrode trajectories (Fig. 3).]

The finding of short-latency, auditory-responsive cells in the posterolateral thalamus of cats provides new evidence that the
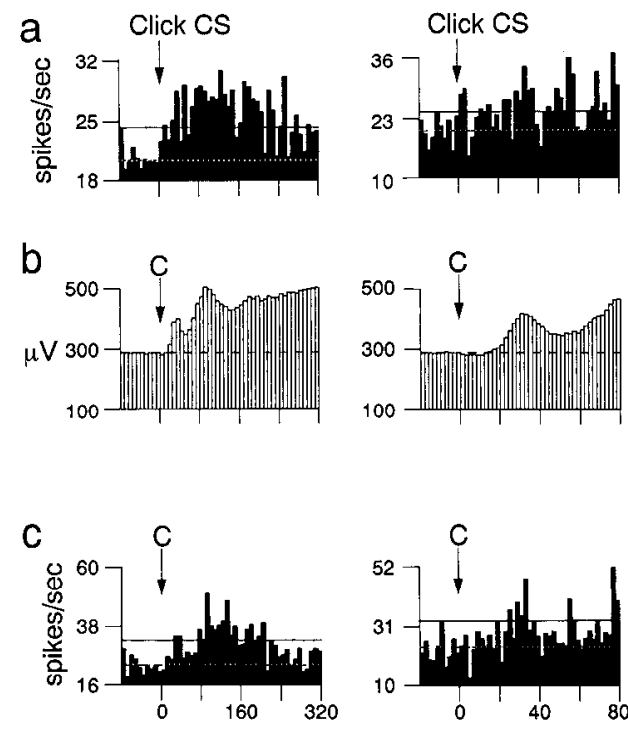

d

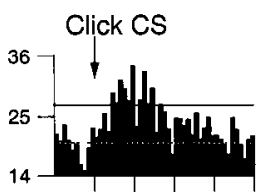

e

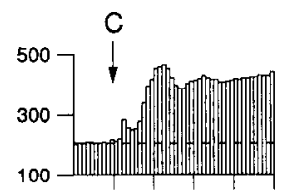

f

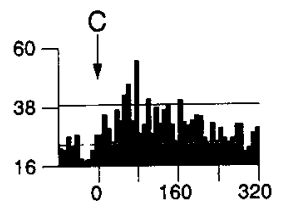

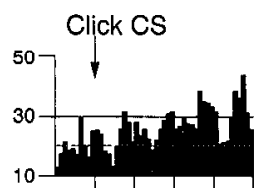
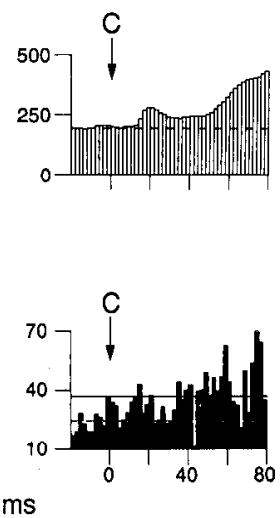

Figure 7. $a$ and $c$, Histogram averages of activity of units (solid bars) responsive to click CS from all conditioned animals. $b$, EMG activity (open bars), recorded from orbicularis oculi muscles concurrently with the spike data obtained in $a$. Inclusive criterion used to define responsive units in $a$; selective criteria in $c$ (see Materials and Methods for further explanation). The averages are shown at different time scales to permit comparison of timing between spike activity and the conditioned EMG response. Data in $a-c$ are from midthalamus; $d-f$ show corresponding data from posterolateral thalamus. Time calibrations in lower histograms apply to those above as well. 
Table 2. A comparison of changes in patterns of activity to click CS and hiss DS (see Fig. 5) and number of auditory responsive cells (see Table 1) after conditioning (relative to naive state) shows differences between mid- and posterolateral thalamus of conscious cats

\begin{tabular}{lll} 
& \multicolumn{2}{l}{ Region of thalamus } \\
\cline { 2 - 3 } & $\begin{array}{l}\text { Mid- } \\
\text { thalamus }\end{array}$ & $\begin{array}{l}\text { Posterolateral } \\
\text { thalamus }\end{array}$ \\
\hline $\begin{array}{l}\text { Spontaneous firing } \\
\begin{array}{l}\text { Peak activity in } \\
\text { response to CS }\end{array}\end{array}$ & $\begin{array}{l}\text { Slight increase } \\
\text { Increase }\end{array}$ & $\begin{array}{l}\text { Decrease } \\
\text { No change/ } \\
\text { slight decrease }\end{array}$ \\
$\begin{array}{l}\text { Peak activity in } \\
\text { response to DS }\end{array}$ & Slight increase & Decrease \\
$\begin{array}{l}\text { Number of CS-responsive } \\
\text { cells }\end{array}$ & No change & No change \\
$\begin{array}{l}\text { Number of DS-responsive } \\
\text { cells }\end{array}$ & No change & Decrease \\
\end{tabular}

a Note, however, that the $\mathrm{S}: \mathrm{N}$ ratio (peak magnitude vs baseline) of the response to the CS increased after conditioning (Fig. 5).

lateralis posterior-pulvinar complex should be regarded as an auditory as well as a visual relay nucleus (Godfraind et al., 1972; Veraart et al., 1972; Giuliano et al., 1977). One earlier study demonstrated auditory responsive cells in the PO thalamic complex of anesthetized cats (Phillips and Irvine, 1979; also see Imig and Morel, 1985) but failed to find such units in the pulvinar-lateralis posterior complex. Our evidence agrees with earlier findings in rats that the pulvinar complex contains many short ( $<20 \mathrm{msec}$ )-latency, auditory-responsive units whose discharge properties change with conditioning (Olds et al., 1972).

Cats can perform behavioral responses to selected auditory stimuli after ablation of the auditory cortex (Neff, 1961). Some of these responses, such as the short-latency blink CR, depend on the rostral, motor cortex being intact (Woody et al., 1974). The onset latency $(14 \mathrm{msec})$ of the posterolateral thalamic responses to auditory stimuli in our cats lagged that of units of the auditory and motor cortex (Goldstein et al., 1960; Evans and Whitfield, 1964; Woody et al., 1970; de Ribaupierre et al., 1972; Sakai and Woody, 1980). Thus, the posterolateral thalamus would not support the fastest auditory transmissions to the cortex but could still support brainstem-generated motor responses to auditory stimuli (cf. Tischler and Davis, 1983) and longer-latency cortically mediated responses (Sakai and Woody, 1980). The onset latency of the auditory-responsive cells of the mid-thalamus in cat was $28 \mathrm{msec}$, thus lagging initiation (20 msec onset after click CS) of the blink CR.

Substantial differences were found in auditory transmission and processing between mid-and posterolateral thalamus (Table 2). Differences in baseline activity were demonstrated between mid- and posterolateral thalamic areas before conditioning was begun in averages made across cats as well as in single animals. The ways in which the patterns of activity to click and hiss changed after discriminative conditioning also differed between thalamic regions even though each area developed a greater response to the CS than the DS. In the mid-thalamus, the peak magnitude of response to the CS was enhanced. In the posterolateral thalamus, the peak magnitude did not increase but the baseline activity decreased in such a way that the $S: N$ ratio of the response to the CS was enhanced. The numbers of DSresponsive cells also decreased. Again, the changes within single animals agreed with those across groups of animals. Thus, these differences in processing reflected differences between thalamic regions as opposed to differences between individual animals.

Not only did the forms of coding and processing represented by the changes differ between mid- and posterolateral thalamus, but they also differed from the coding and processing serving discrimination of similar stimuli in cortical auditory-motor areas. In the motor cortex, the number of cells responding to the CS and magnitude of response increased after blink conditioning but the rate of baseline activity remained unchanged (Engel and Woody, 1972). In the auditory association cortex, the number of cells responding to the CS did not increase but both baseline activity and the magnitude of response to the CS increased (Woody et al., 1976). We conclude that different forms of information processing support discrimination between auditory stimuli in each of these areas and that thalamic involvement in this processing is much greater than previously thought.

\section{References}

Chizhevsky V, Woody CD, Gruen E, Melamed O (1990) Oversized, auditory responsive units of rostral, mid, and posterolateral thalamus. NeuroReport 1:89-92.

de Ribaupierre F, Goldstein MH, Yeni-Koshian G (1972) Intracellular study of the cat's primary auditory cortex. Brain Res 48:185-204.

Engel J Jr, Woody CD (1972) Effects of character and significance of stimulus on unit activity at coronal-pericruciate cortex of cat during performance of conditioned motor response. J Neurophysiol 35:220229.

Evans EF, Whitfield IC (1964) Classification of unit responses in the auditory cortex of the unanesthetized, unrestrained cat. J Physiol (Lond) 171:476-493.

Gabriel M, Kubota Y, Shenker J (1988) Limbic circuit interactions during learning. In: Information processing in the brain (Markowitsch HJ, ed), pp 39-63. Toronto: Huber.

Gerfen CR, Sawchenko PE (1984) An anterograde neuroanatomical tracing method that shows the detailed morphology of neurons, their axons and terminals: immunohistochemical localization of an axonally transported plant lectin, Phaseolus vulgaris leucoagglutinin (PHA-L). Brain Res 290:219-238.

Giuliano A, Spreafico R, Broggi G, Giovannini P, Franceschetti S (1977) Topographic distribution of visual and somesthesic unitary responses in the Pul-LP complex of the cat. Neurosci Lett 4:135-143.

Godfraind J-M, Meulders M, Veraart C (1972) Visual properties of neurons in pulvinar, nucleus lateralis posterior and nucleus suprageniculatus thalami in the cat. I. Qualitative investigation. Brain Res 44:503-526.

Goldstein MH Jr, Abeles M, Daly RL, McIntosh J (1960) Functional architecture in cat primary auditory cortex: tonotopic organization. J Neurophysiol 33:188-197.

Graybiel AM (1972) Some ascending connections of the pulvinar and lateralis posterior of the thalamus in the cat. Brain Res 44:99-125.

Heath CJ, Jones EG (1971) An experimental study of the ascending connections from the posterior group of thalamic nuclei in the cat. $J$ Comp Neurol 141:397-426.

Hirano T, Woody C, Birt D, Aou S, Miyake J, Nenov V (1987) Pavlovian conditioning of discriminatively elicited eyeblink responses with short onset latency attributable to lengthened interstimulus intervals. Brain Res 400:171-175.

Imig TJ, Morel A (1983) Organization of the thalamocortical auditory system in the cat. Annu Rev Neurosci 6:95-120.

Imig TJ, Morel A (1985) Tonotopic organization in the lateral part of posterior group of thalamic nuclei in the cat. J Neurophysiol 53: $836-851$.

Irvine DRF, Phillips DP (1982) Polysensory "association" areas of the cerebral cortex. In: Cortical sensory organization, Vol 3, Multiple auditory areas (Woolsey CN, ed), pp 111-156. Clifton, NJ: Humana.

Jones EG, Leavitt RY (1974) Retrograde axonal transport and the demonstration of non-specific projections to the cerebral cortex and striatum from thalamic intralaminar nuclei in the rat, cat and monkey. J Comp Neurol 154:349-378.

Kim EH-J, Woody CD, Berthier NE (1983) Rapid acquisition of con- 
ditioned eye blink responses in cats following pairing of an auditory CS with glabella tap US and hypothalamic stimulation. J Neurophysiol 49:767-779.

LeDoux JE, Farb C, Ruggiero DA (1990) Topographic organization of neurons in the acoustic thalamus that project to the amygdala. $\mathbf{J}$ Neurosci 10:1043-1054.

Macchi G, Bentivoglio M, D'atena C, Rossini P, Tempesta E (1977) The cortical projections of the thalamic intralaminar nuclei restudied by means of the HRP retrograde axonal transport. Neurosci Lett 4: 121-126.

Melamed O, Woody CD (1989) Responses of cells of laterodorsal and lateral posterior thalamus to auditory stimuli before and after conditioning of a Pavlovian eyeblink reflex. Soc Neurosci Abstr 15:889.

Neff WD (1961) Neural mechanisms of auditory discrimination. In: Sensory communication (Rosenblith WA, ed), pp 259-278. Cambridge, MA: MIT Press.

Olds J, Disterhoft JF, Segal M, Kornblith CL, Hirsh R (1972) Learning centers of rat brain mapped by measuring latencies of conditioned unit responses. J Neurophysiol 35:202-219.

Phillips DP, Irvine DRF (1979) Acoustic input to single neurons in pulvinar-posterior complex of cat thalamus. J Neurophysiol 42:123136.

Porter L, Sakamoto K (1988) The organization and synaptic relationship of the projection from the primary sensory to the primary motor cortex in the cat. J Comp Neurol 271:387-396.

Sakai H, Woody CD (1980) Identification of auditory responsive cells in coronal-pericruciate cortex of awake cats. J Neurophysiol 44:223231.

Sakai M, Sakai H, Woody C (1978) Intracellular staining of cortical neurons by pressure microinjection of horseradish peroxidase and recovery by core biopsy. Exp Neurol 58:138-144.

Snider RS, Niemer WT (1961) Stereotaxic atlas of the cat brain. Chicago: University of Chicago.

Steriade M, Glenn LL (1982) Neocortical and caudate projections of intralaminar thalamic neurons and their synaptic excitation from midbrain reticular core. J Neurophysiol 48:352-371.
Steriade M, Diallo A, Oakson G, White-Guay B (1977) Some synaptic inputs and ascending projections of lateralis posterior thalamic neurons. Brain Res 131:39-53.

Tischler MD, Davis M (1983) A visual pathway that mediates fear conditioned enhancement of acoustic startle. Brain Res 276:55-71.

Veraart C, Meulders M, Godfraind M-M (1972) Visual properties of neurons in pulvinar, nucleus lateralis posterior and nucleus suprageniculatus thalami in the cat. II. Quantitative investigation. Brain Res 44:527-546.

Weinberger NM, Diamond DM (1987) Physiological plasticity in auditory cortex: rapid induction by learning. Prog Neurobiol 29:1-55.

Winer BJ (1971) Statistical principles in experimental design, 2d ed. New York: MacGraw.

Woody CD, Black-Cleworth P (1973) Differences in excitability of cortical neurons as a function of motor projection in conditioned cats. J Neurophysiol 36:1104-1116.

Woody CD, Vassilevsky NN, Engel J Jr (1970) Conditioned eye blink: unit activity at coronal-precruciate cortex of the cat. J Neurophysiol $33: 851-864$

Woody C, Yarowsky P, Owens J, Black-Cleworth P, Crow T (1974) Effect of lesions of cortical motor areas on acquisition of conditioned eyeblink in the cat. J Neurophysiol 37:385-394.

Woody CD, Knispel JD, Crow TJ, Black-Cleworth PA (1976) Activity and excitability to electrical current of cortical auditory receptive neurons of awake cats as affected by stimulus association. J Neurophysiol 39:1045-1061.

Woody CD, Gruen E, McCarley K (1984) Intradendritic recording from neurons of motor cortex of cats. J Neurophysiol 51:925-938.

Woody CD, Gruen E, Birt D (1991a) Changes in membrane currents during Pavlovian conditioning of single cortical neurons. Brain Res 539:76-84

Woody CD, Gruen E, Melamed O, Chizhevsky V (1991b) Patterns of unit activity in rostral thalamus of cats related to short latency discrimination between different auditory stimuli. J Neurosci 11:48-58. 